\title{
Activating mutations of the $G N A Q$ gene: a frequent event in primary melanocytic neoplasms of the central nervous system
}

\author{
Heidi V. N. Küsters-Vandevelde • Annelies Klaasen • Benno Küsters • Patricia J. T. A. Groenen • \\ Ilse A. C. H. van Engen-van Grunsven • Marcory R. C. F. van Dijk • Guido Reifenberger • \\ Pieter Wesseling • Willeke A. M. Blokx
}

Received: 12 September 2009/Revised: 9 November 2009/Accepted: 9 November 2009/Published online: 22 November 2009

(C) The Author(s) 2009. This article is published with open access at Springerlink.com

\begin{abstract}
Primary melanocytic neoplasms of the central nervous system (CNS) are uncommon neoplasms derived from melanocytes that normally can be found in the leptomeninges. They cover a spectrum of malignancy grades ranging from low-grade melanocytomas to lesions of intermediate malignancy and overtly malignant melanomas. Characteristic genetic alterations in this group of neoplasms have not yet been identified. Using direct sequencing, we investigated 19 primary melanocytic lesions of the CNS (12 melanocytomas, 3 intermediategrade melanocytomas, and 4 melanomas) for hotspot oncogenic mutations commonly found in melanocytic tumors of the skin (BRAF, NRAS, and HRAS genes) and uvea ( $G N A Q$ gene). Somatic mutations in the GNAQ gene at codon 209, resulting in constitutive activation of GNAQ, were detected in 7/19 (37\%) tumors, including 6/12 melanocytomas, 0/3 intermediate-grade melanocytomas, and
\end{abstract}

H. V. N. Küsters-Vandevelde $(\bowtie) \cdot$ P. Wesseling Department of Pathology C66, Canisius Wilhelmina Hospital, P.O. Box 9015, 6500 GS Nijmegen, The Netherlands e-mail: h.vandevelde@pathol.umcn.nl

A. Klaasen · B. Küsters · P. J. T. A. Groenen · I. A. C. H. van Engen-van Grunsven · P. Wesseling · W. A. M. Blokx

Department of Pathology, Radboud University Nijmegen Medical Centre, P.O. Box 9100, 6500 HB Nijmegen,

The Netherlands

M. R. C. F. van Dijk

Department of Pathology and Medical Biology,

University Medical Centre Groningen, P.O. Box 30001,

9700 RB Groningen, The Netherlands

\section{G. Reifenberger}

Institute of Neuropathology, University Hospital,

Heinrich Heine University, Moorenstraße 5,

40225 Düsseldorf, Germany
$1 / 4$ melanomas. These GNAQ-mutated tumors were predominantly located around the spinal cord (6/7). One melanoma carried a $B R A F$ point mutation that is frequently found in cutaneous melanomas (c.1799 T>A, p.V600E), raising the question whether this is a metastatic rather than a primary tumor. No HRAS or NRAS mutations were detected. We conclude that somatic mutations in the GNAQ gene at codon 209 are a frequent event in primary melanocytic neoplasms of the CNS. This finding provides new insight in the pathogenesis of these lesions and suggests that $G N A Q$-dependent mitogen-activated kinase signaling is a promising therapeutic target in these tumors. The prognostic and predictive value of $G N A Q$ mutations in primary melanocytic lesions of the CNS needs to be determined in future studies.

Keywords Primary melanocytic neoplasms . Melanocytoma $\cdot G N A Q$ - Central nervous system . MAP kinase pathway

\section{Introduction}

Primary melanocytic neoplasms of the central nervous system (CNS) are uncommon neoplasms occurring in diffuse or localized form [5, 8]. Diffuse lesions such as melanocytosis and melanomatosis generally occur in the setting of dermatologic syndromes (neurocutaneous melanosis, nevus of Ota) $[1,16,18]$. Localized lesions present as leptomeningeal masses and consist of a spectrum ranging from 'well differentiated' melanocytomas to lesions of intermediate malignancy and overtly malignant melanomas [6]. They are derived from scattered melanocytes that are normally present in the leptomeninges, especially at the base of the brain, in the posterior fossa and around the 
upper cervical spinal cord. Melanocytomas are solitary, low-grade tumors that do not invade surrounding structures [5]. They are usually characterized by a benign clinical course, but local recurrence can occur [14, 25]. Intermediate grade lesions show histological features suggestive of aggressive behavior, such as invasion of the CNS but lack the overt cytological atypia of melanomas [6]. The biological behavior of intermediate-grade melanocytomas is unclear [5]. Primary melanomas of the CNS occur throughout the neuroaxis with a predilection for the spinal cord and posterior fossa. They are cytologically similar to melanomas arising in other sites and may metastasize to remote organs. Diffuse spreading of a primary meningeal melanoma through the subarachnoid space is referred to as meningeal melanomatosis $[5,27]$. Discrimination between primary and metastatic melanocytic lesions of the CNS is important, because patients with metastatic disease carry a worse prognosis, with a life expectancy of less than 1 year in most studies [7, 23]. In addition, in some cases of primary melanomas of the CNS, long-term survival and even 'cures' have been documented after complete surgical excision [6, 29]. However, especially in cases where the melanocytic tumor presents as a solitary mass in the meninges and the patient is not known to have a melanocytic tumor of the skin, this differential diagnosis can be very difficult, both at the clinical and histological levels. While the molecular genetics of cutaneous melanomas has been investigated in numerous studies, the genetic alterations underlying primary CNS melanocytic lesions have not yet been addressed [5]. In melanocytic lesions of the skin-benign nevi as well as melanomas-oncogenic mutations in signaling components of the MAP kinase pathway are frequent $[11,22]$. These mutations mostly involve exon 15 of the $B R A F$ gene and exon 3 (codon 61) of the proto-oncogene NRAS. Mutations in HRAS are less frequent $[13,20]$. Recently, in uveal melanomas and in some intradermal melanocytic lesions, such as blue nevi and nevi of Ota, somatic activating mutations of the GNAQ gene (or ' $\mathrm{G}$ alpha q gene') at codon 209 have been reported $[17,32]$. The $G N A Q$ gene maps on chromosome 9q21, and encodes a heterotrimeric GTP-binding protein $\alpha$-subunit that couples G-protein coupled receptor signaling to the MAP kinase pathway [24]. GNAQ codon 209 mutations form an alternative route to MAP kinase activation [32]. In the present study, we investigated the mutation status of the GNAQ, BRAF, NRAS, and HRAS genes in a group of 19 primary melanocytic lesions of the CNS and found that somatic mutations in the GNAQ gene at codon 209 are relatively frequently present in these tumors. While the exact diagnostic, prognostic, and predictive value of $G N A Q$ mutations in primary melanocytic lesions of the CNS is not yet clear, it is to be expected that a better knowledge of the genetic background of these lesions may not only facilitate adequate diagnosis but also identification of (novel) therapeutic targets, and thereby ultimately may have predictive value as well.

\section{Materials and methods}

Patients and histopathology

For this retrospective study, formalin-fixed and paraffinembedded (FFPE) tissues of 19 primary melanocytic lesions of the CNS were retrieved from archives of various Departments of Pathology in The Netherlands and Germany. Cases from the Netherlands diagnosed between 1991 and 2009 were obtained through the Dutch nationwide histopathology and cytopathology data network and archive (PALGA) [9]. The study was performed in accordance with the ethical standards for this type of investigation in The Netherlands. Histology was revised by two pathologists (HK, BK). The diagnosis of 'melanocytoma', 'intermediate-grade melanocytoma' or 'melanoma' was based on histomorphological criteria, as described by Brat et al. [5, 6], and immunohistochemical stains (S100 positivity and at least one additional melanocytic marker (HMB45 or MelanA) positive in combination with lack of EMA staining). Scoring of histology included nuclear pleomorphism (mild, moderate or severe), mitotic activity, necrosis, melanin pigmentation, and CNS invasion.

\section{DNA extraction}

About three manually dissected sections of 10- $\mu \mathrm{m}$ FFPE tissue with an estimated tumor cell percentage of at least $60 \%$ were used for DNA extraction. After deparaffinization and rehydration, the tissues sections were incubated in proteinase $\mathrm{K}$, followed by subsequent affinity-purification of the DNA (QIAGEN GmbH, Germany). DNA sample concentration was assessed spectrophotometrically (260/ $280 \mathrm{~nm}$ using a NanoDrop spectrophotometer, Peqlab Biotechnologies, Erlangen, Germany). DNA quality of the samples was tested using the BIOMED-2 gene control PCR, in which gene segments of house-keeping genes are amplified, yielding different fragment sizes $(100,200,300$, and $400 \mathrm{bp}$ ), depending on the extent of fragmentation of the DNA [31]. All extracted DNA samples allowed amplification of at least the 200-bp amplicon of the BIOMED-2 gene control PCR.

Mutation analyses

Direct sequence analysis of the GNAQ, BRAF, NRAS, and $H R A S$ genes was performed on 19 primary melanocytic lesions of the CNS. Exon 5 of $G N A Q$, harboring codon 209 
which is essential for GTP hydrolysis, was sequenced [19]. Furthermore, we performed sequence analysis of exon 15 of BRAF and exon 3 of NRAS and HRAS, since these are well known hotspot regions for oncogenic mutations in melanocytic lesions of the skin $[2,13,20]$. Primer sequences used are listed in Table 1. All primers, except for $G N A Q$, contained a M13 forward or reverse consensus sequence for sequencing the different exons. PCR amplification of exon 5 of $G N A Q$ was performed in a total volume of $25 \mu \mathrm{L}$, containing $50 \mathrm{ng}$ DNA, PCR-buffer IV (Integro), $37 \mathrm{mM} \mathrm{MgCl}, 250 \mu \mathrm{M}$ of each deoxynucleotide triphosphate, $37.5 \mu \mathrm{g}$ bovine serum albumin (Sigma), 10 pmol of each primer, and 0.05 units of thermostable DNA polymerase (Sigma). DNA amplification was performed in a PTC 200 Thermal Cycler (MJ Research). The PCR was started with $5 \mathrm{~min}$ at $92^{\circ} \mathrm{C}$ and followed with 35 cycles of denaturation $45 \mathrm{~s}$ at $94^{\circ} \mathrm{C}$, annealing at $62^{\circ} \mathrm{C}$ for $45 \mathrm{~s}$ and extension at $72^{\circ} \mathrm{C}$ for $45 \mathrm{~s}$, followed by a final extension at $72^{\circ} \mathrm{C}$ for $20 \mathrm{~min}$ and cooling down for $5 \mathrm{~min}$ at $20^{\circ} \mathrm{C}$. PCR amplification of exon 15 of $B R A F$ and exon 3 of NRAS and HRAS were performed in a total volume of $20 \mu \mathrm{L}$. The PCR mix contained 50 ng DNA, buffer IV (Integro), $3 \mathrm{mM} \mathrm{MgCl} 2,200 \mu \mathrm{M}$ of each deoxynucleotide triphosphate, $30 \mu \mathrm{g}$ bovine serum albumin (Sigma), 10 pmol of each primer, and 0.25 units of thermostable DNA polymerase (Sigma). DNA amplification was performed in a PTC 200 Thermal Cycler (MJ Research). The PCR was started with $5 \mathrm{~min}$ at $94^{\circ} \mathrm{C}$ and followed with 30 cycles of denaturation $45 \mathrm{~s}$ at $94^{\circ} \mathrm{C}$, annealing at $60^{\circ} \mathrm{C}$ for $45 \mathrm{~s}$ and extension at $72^{\circ} \mathrm{C}$ for $45 \mathrm{~s}$, with a final extension at $72^{\circ} \mathrm{C}$ for $5 \mathrm{~min}$. All PCR products were purified with MinElute plates (Qiagen). One microliter of the PCR product was used for the sequence reaction on a $\mathrm{ABI}$ PRISM 3700 DNA analyzer (Applied Biosystems). Both strands were sequenced using the M13 primers. For all mutations detected, normal tissue was tested to exclude germline mutations (archival FFPE skin tissue).

Table 1 Primers used for mutation analyses

\begin{tabular}{llll}
\hline Gene & Exon & $\begin{array}{l}\text { Forward }(\mathrm{Fw}) \\
\text { Reverse }(\mathrm{Rv})\end{array}$ & Primer sequence $5^{\prime}-3^{\prime}$ \\
\hline \multirow{2}{*}{ GNAQ } & 5 & $\mathrm{Fw}$ & TTCCCTAAGTTTGTAAGTAGTGC \\
& & $\mathrm{Rv}$ & ATCCATTTTCTTCTCTCTGACC \\
BRAF & 15 & $\mathrm{Fw}$ & CCTTTACTTACTACACCTCAG \\
& & $\mathrm{Rv}$ & AAAAATAGCCTCAATTCTTAC \\
\multirow{2}{*}{ NRAS } & 3 & $\mathrm{Fw}$ & GATTCTTACAGAAAACAAGTGG \\
& & $\mathrm{Rv}$ & TAATGCTCCTAGTACCTGTACAG \\
HRAS & 3 & $\mathrm{Fw}$ & CTGCAGGATTCCTACCGGA \\
& & $\mathrm{Rv}$ & ACT TGGTGTTTGTTGATGGCA \\
\hline
\end{tabular}

\section{Results}

Patient and histopathological characteristics

Our study group consisted of 12 melanocytomas, 3 intermediate-grade melanocytomas and 4 primary melanomas of the CNS. Table 2 summarizes the respective patient and histopathological characteristics. In each patient, no primary melanoma localizations elsewhere in the body were known to be present. Histology revealed melanocytomas as being often heavily pigmented lesions consisting of spindle and/or epithelioid cells arranged in fascicles, sheets and/or compact nests (Fig. 1a, b). Nucleoli were inconspicuous. Mitotic activity was low (0-1 per $10 \mathrm{HPFs})$. In some cases focal necrosis was present. Nuclear pleomorphism was mostly mild. As summarized in Table 2 the melanocytomas often recurred. Three tumors were classified as intermediate-grade melanocytomas based on increased mitotic activity (2-5 per $10 \mathrm{HPF}$ ) and CNS invasion (patients 1, 6, and 17) (Fig. 1b, c). In the melanomas, nuclear pleomorphism was prominent, together with conspicuous nucleoli, higher mitotic activity ( $>7$ per $10 \mathrm{HPF}$ ) and often extensive necrosis (Fig. 1d). All lesions were positive for S100, HMB-45 and/or MelanA, and lacked staining for EMA, the latter to exclude melanotic meningioma.

\section{Mutation analyses}

In this group of 19 primary melanocytic neoplasms of the CNS, we detected 7 mutations in the GNAQ gene (37\%) (Table 3). All mutations were present in codon 209 (p.Gln209Pro and p.Gln209Leu) and were somatic mutations (Fig. 2). Of these seven GNAQ mutant lesions, six were melanocytomas (50\%) and one was a melanoma (1/4, $25 \%)$. The intermediate-grade melanocytomas $(n=3)$ contained no mutations in the GNAQ gene. Of the GNAQmutated melanocytomas, five were located in the leptomeninges of the spinal cord and one attached to the tentorium cerebelli. All but one GNAQ-mutated melanocytomas were strongly pigmented. The one melanoma containing a GNAQ mutation was located in the spinal cord (sacral) and was mildly pigmented. Mutation analysis of the $B R A F$ gene revealed one $B R A F$ mutation (c.1799 $\mathrm{T}>\mathrm{A}$, p.V600E), in a melanoma. No HRAS or NRAS mutations were detected in any of the samples.

\section{Discussion}

Primary melanocytic tumors of the CNS consist of a spectrum of rare neoplasms derived from scattered melanocytes located in the leptomeninges. These melanocytes 
Table 2 Patient and histopathological characteristics

\begin{tabular}{|c|c|c|c|c|c|c|c|c|c|c|c|}
\hline Patient & Sex & Age & Diagnosis $^{\mathrm{a}}$ & Location $^{\mathrm{b}}$ & $\begin{array}{l}\text { Cell } \\
\text { type }^{\mathrm{c}}\end{array}$ & $\begin{array}{l}\text { Nuclear } \\
\text { pleomorphism }^{\mathrm{d}}\end{array}$ & Mitoses $^{\mathrm{e}}$ & Necrosis $^{\mathrm{f}}$ & $\begin{array}{l}\text { CNS } \\
\text { invasion }\end{array}$ & Pigmentation $^{\mathrm{g}}$ & $\begin{array}{l}\text { Available } \\
\text { follow-up }\end{array}$ \\
\hline 1 & $\mathrm{~F}$ & 50 & IM & Th11-12 & $\mathrm{S}$ & ++ & 2 & - & Yes & + & na \\
\hline 2 & $\mathrm{~F}$ & 27 & $\mathrm{MC}$ & $\begin{array}{l}\text { Right cerebello-pontine } \\
\text { angle }\end{array}$ & $\mathrm{E}$ & + & 0 & - & $\mathrm{na}^{\mathrm{h}}$ & No & na \\
\hline 3 & M & 41 & $\mathrm{MC}$ & $\mathrm{C} 0-\mathrm{C} 3$ & $\mathrm{E}$ & $+(+)$ & 0 & + & na & +++ & na \\
\hline 4 & na & na & MM & $\mathrm{LM}^{\mathrm{b}}$ & $\mathrm{E}$ & ++ & $>15$ & - & na & No & na \\
\hline 5 & na & na & $\mathrm{MC}$ & LM & Mx & $+(+)$ & 1 & + & na & + & $\mathrm{R}$ \\
\hline 6 & $\mathrm{~F}$ & 68 & $\mathrm{IM}$ & Cerebellar tentorium & $\mathrm{E}$ & + & 5 & - & Focal & + & na \\
\hline 7 & M & 27 & $\mathrm{MC}$ & Cerebellar tentorium & Mx & + & 1 & - & No & ++ & na \\
\hline 8 & $\mathrm{~F}$ & 44 & $\mathrm{MC}$ & Pineal region & $\mathrm{S}$ & + & 1 & - & No & + & na \\
\hline 9 & M & 55 & $\mathrm{MC}$ & C3-6 & $\mathrm{Mx}$ & + & 0 & - & na & ++ & $\mathrm{R}$ \\
\hline 10 & $\mathrm{~F}$ & 59 & MM & S2 & Mx & +++ & 8 & ++ & Yes & + & na \\
\hline 11 & na & na & $\mathrm{MC}$ & C5-6 & $\mathrm{E}$ & + & 0 & - & na & +++ & $\mathrm{R}$ \\
\hline 12 & M & 41 & $\mathrm{MC}$ & Th6 & $\mathrm{S}$ & + & 0 & + & No & +++ & $\mathrm{R}$ \\
\hline 13 & $\mathrm{~F}$ & 45 & $\mathrm{MC}$ & L3-4 & $\mathrm{Mx}$ & $+(+)$ & 0 & - & na & +++ & $\mathrm{R}$ \\
\hline 14 & na & na & $\mathrm{MC}$ & Th11 & $\mathrm{S}$ & + & 1 & - & na & + & na \\
\hline 15 & M & 49 & MM & Frontal lobe left & $\mathrm{E}$ & ++ & 7 & +++ & na & No & na \\
\hline 16 & na & na & $\mathrm{MC}$ & Cerebellar & $\mathrm{S}$ & + & 0 & - & No & ++ & na \\
\hline 17 & na & na & $\mathrm{IM}$ & LM & $\mathrm{E}$ & + & 2 & - & Yes & +++ & na \\
\hline 18 & na & na & $\mathrm{MC}$ & na & $\mathrm{S}$ & + & 0 & - & na & +++ & na \\
\hline 19 & M & 7 & MM & Temporal lobe right & $\mathrm{E}$ & +++ & $>10$ & - & Yes & + & $\begin{array}{l}\text { Cong. } \\
\text { nevus }{ }^{\mathrm{i}}\end{array}$ \\
\hline
\end{tabular}

$F$ female; $M$ male; $n a$ not analyzed/data not available; $R$ recurred

a Diagnosis: $M C$ melanocytoma; $M M$ melanoma; $I M$ intermediate grade melanocytoma

b Location: $L M$ leptomeningeal (more specific information about location could not be retrieved)

c Cell type: $S$ spindle; $E$ epithelioid; $M x$ mixed

${ }^{\mathrm{d}}$ Scoring of nuclear pleomorphism: + mild; ++ moderate; +++ severe

e Number of mitotic figures per $10 \mathrm{HPF}$

${ }^{\mathrm{f}}$ Scoring of necrosis: + focal; ++ moderate; +++ extensive

g Scoring of pigmentation: + mild; ++ moderate +++ severe

h $n a$ no CNS tissue present in slide for analysis

${ }^{i}$ Patient known with a giant congenital melanocytic nevus

are derived from the neural crest during early embryonic development and are most frequently encountered in the recesses of the sulci at the base of the brain and around the brain stem and upper part of the cervical spinal cord [12]. Up to now, the genetic alterations associated with these neoplasms are unknown. There is an increasing evidence that melanocytic neoplasms in general are a heterogeneous group of tumors with different molecular changes in melanocytic lesions from different body sites. Most melanocytic nevi and melanomas of the skin show oncogenic mutations in signaling components of the MAP kinase pathway, in particular BRAF and NRAS [11, 22], although in uveal melanoma, Spitz nevi and blue nevi, these mutations are infrequent [26]. Very recently, mutations in the GNAQ gene at codon 209 were described as an alternative route to MAP kinase activation in a particular subgroup of melanocytic neoplasms, namely uveal melanomas and specific intradermal melanocytic lesions such as blue nevi and nevi of Ota [17, 32]. We analyzed a group of 19 primary melanocytic lesions of the CNS for hotspot oncogenic mutations as described in melanocytic tumors of the skin (exon 15 of $B R A F$ gene, exon 3 of $N R A S$, and exon 3 of $H R A S$ ) and uvea (exon 5 of $G N A Q$ ). In 7 out of these 19 CNS melanocytic tumors a somatic GNAQ mutation was present at codon 209 (37\%). This gene is located on chromosome $9 \mathrm{q} 21$ and encodes GTP-binding proteins, a family of heterotrimeric proteins that couple cell surface receptors to intracellular signaling pathways, such as the MAP kinase pathway. Codon 209 encodes the catalytic domain of GNAQ. Mutations in this catalytic domain prevent hydrolysis of GTP and turns GNAQ into its active, GTP-bound state. In uveal melanomas, identical somatic 
Fig. 1 Heavily pigmented melanocytoma adjacent to the thoracic spinal cord (patient 12) consisting of spindle cells arranged in fascicles (a) (magnification $400 \times$ ).

Epithelioid cell morphology in an intermediate-grade melanocytoma (patient 17) showing increased mitotic activity (2/10 HPFs) (b) (arrow) (magnification 200×). Intermediate-grade melanocytoma showing invasion in the thoracic spinal cord (c) (patient 1); note the Rosenthal fiber (arrow) in the surrounding neuropil (magnification $200 \times$ ). Strong nuclear pleomorphism and high mitotic activity (arrows) in a melanoma in the sacral region (d) (patient 10) (magnification $200 \times)$

Table 3 Mutation analysis of the GNAQ, BRAF, NRAS, and HRAS genes
MC melanocytoma; $M M$ melanoma; $I M$ intermediate grade melanocytoma; na mutation status could not reliably be evaluated due to suboptimal DNA quality, the DNA being derived from formalin-fixed and paraffinembedded tissues
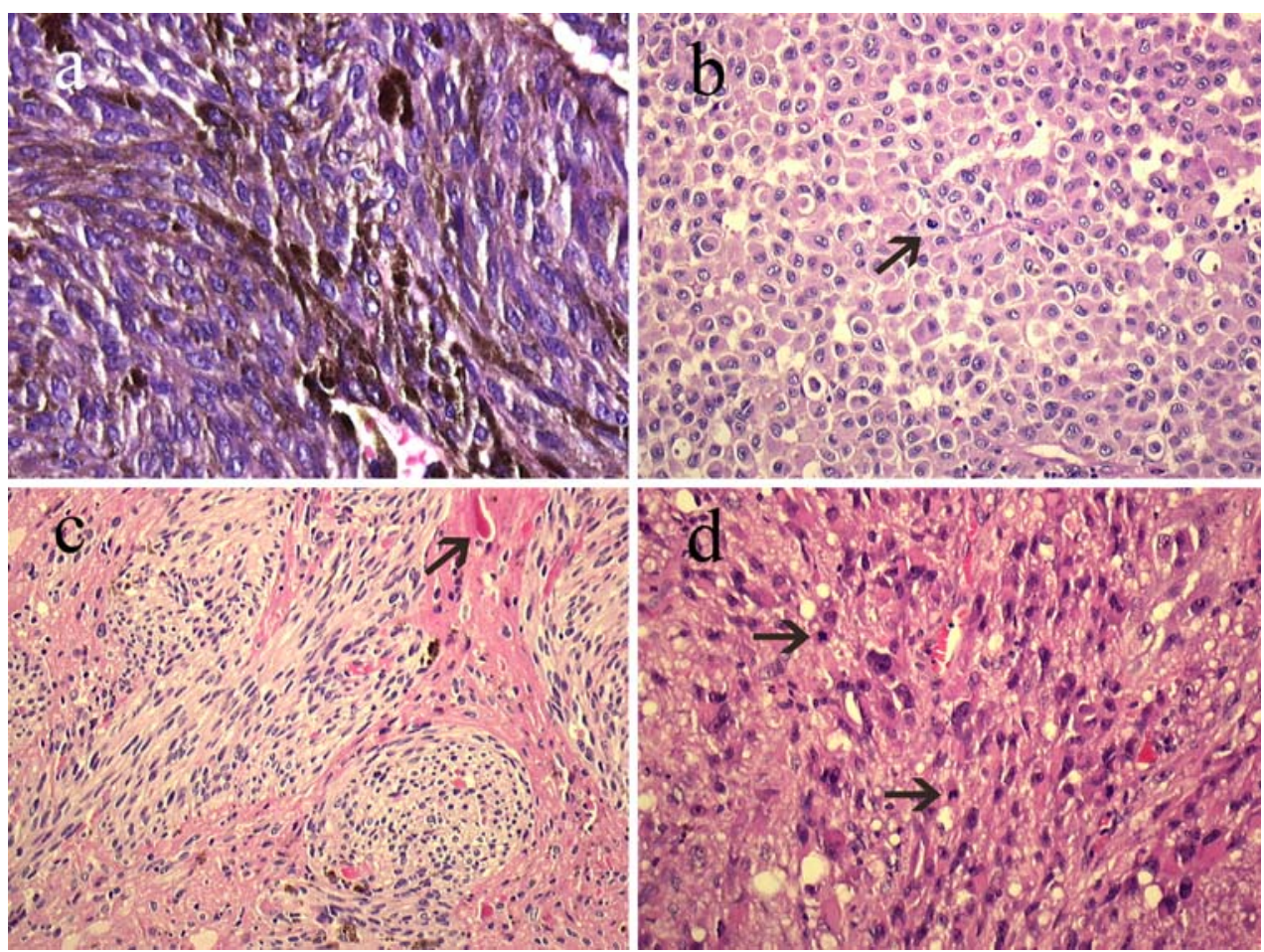

\begin{tabular}{|c|c|c|c|c|c|}
\hline Patient & Diagnosis & $G N A Q$ & $B R A F$ & $N R A S$ & $H R A S$ \\
\hline 1 & $\mathrm{IM}$ & wt & wt & na & na \\
\hline 2 & $\mathrm{MC}$ & wt & wt & wt & na \\
\hline 3 & $\mathrm{MC}$ & c.626 A>C (p.Gln209Pro) & wt & wt & wt \\
\hline 4 & MM & wt & wt & wt & wt \\
\hline 5 & $\mathrm{MC}$ & wt & wt & wt & wt \\
\hline 6 & IM & wt & wt & wt & wt \\
\hline 7 & $\mathrm{MC}$ & c.626 A>C (p.Gln209Pro) & wt & wt & wt \\
\hline 8 & $\mathrm{MC}$ & wt & wt & wt & wt \\
\hline 9 & $\mathrm{MC}$ & c.626 A>C (p.Gln209Pro) & wt & na & wt \\
\hline 10 & $\mathrm{MM}$ & c.626 A>T (p.Gln209Leu) & wt & wt & na \\
\hline 11 & $\mathrm{MC}$ & wt & wt & wt & wt \\
\hline 12 & $\mathrm{MC}$ & c.626 A>T (p.Gln209Leu) & wt & na & na \\
\hline 13 & $\mathrm{MC}$ & c.626 A>T (p.Gln209Leu) & wt & wt & na \\
\hline 14 & $\mathrm{MC}$ & c.626 A>T (p.Gln209Leu) & wt & wt & wt \\
\hline 15 & MM & wt & c.1799 T>A (p.V600E) & na & wt \\
\hline 16 & $\mathrm{MC}$ & wt & wt & wt & $\mathrm{wt}$ \\
\hline 17 & IM & wt & wt & na & na \\
\hline 18 & $\mathrm{MC}$ & wt & wt & wt & wt \\
\hline 19 & $\mathrm{MM}$ & wt & wt & wt & wt \\
\hline
\end{tabular}

mutations of GNAQ at codon 209 have been described [21, 32]. $G N A Q$ is important in melanocyte homeostasis and survival of melanocytes early in neural crest development [28].

The presence of GNAQ mutations in primary melanocytic neoplasms of the CNS as well as in uveal melanomas and intradermal melanocytic proliferations such as nevi of Ota and blue nevi $[17,32]$ is interesting as these lesions share some other features. First of all, these melanocytic tumors are non-epithelium-related neoplasms. GNAQ mutations might, thus, preferentially occur in melanocytes already present in extra-epithelial structures such as dermis 


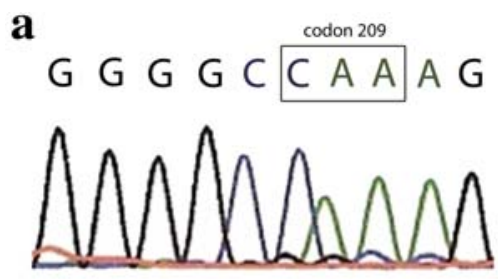

b
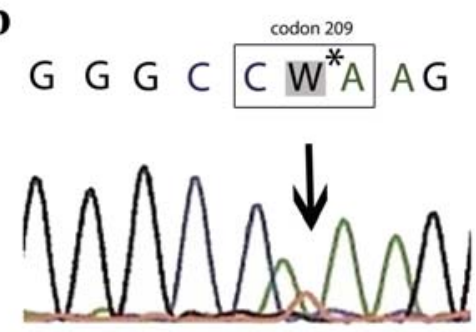

c

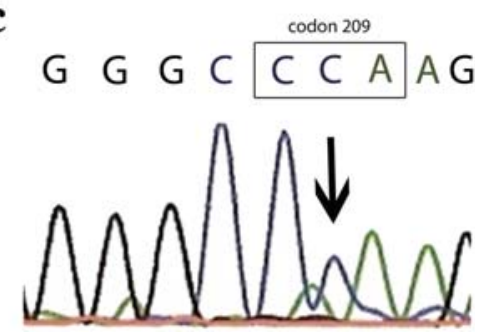

Fig. 2 Sequence tracings for GNAQ surrounding codon 209. Wild type (CAA) (a), CAA > CTA (b), and CAA > CCA (c). *' $\mathrm{W}$ ' is the nucleotide code for $\mathrm{A} / \mathrm{T}$ according to the Kyoto Encyclopedia of Genes and Genomes (http://www.genome.jp/kegg/catalog/codes1.html)

and leptomeninges. Second, they often share strong melanin pigmentation. Third, in this context, the nevus of Ota is interesting because this is a 'dermal melanocytosis', mostly congenital, involving the skin innervated by the first and the second branch of the trigeminal nerve. The nevus of Ota is often associated with 'ocular melanocytosis', involving the sclera, conjunctiva, and uveal tract. The involvement of different anatomical structures in the nevus of Ota might indicate that the $G N A Q$ gene product plays a role in migration of melanocytes early during embryonic development. Histology of this nevus of Ota ranges from scattered dendritic melanocytes to a morphology strongly resembling blue nevi [4]. These nevi of Ota are not only associated with the development of uveal melanoma but are also associated with the presence of CNS melanocytoma [25]. Thus, it appears that GNAQ mutations are preferentially present in a group of non-epithelium-related melanocytic lesions, sharing histological features and occurring in an anatomical distribution indicating a possible role of $G N A Q$ in migration of melanocytes early during embryonic development. Interestingly, tumorigenicity studies in nude mice with injection of human $G N A Q^{Q 209 \mathrm{~L}}$ resulted in heavily pigmented melanocytic tumors at the injection site [32]. Furthermore, dominant dark skin (Dsk) mutations that are found in mutant mice with increased dermal melanin, are mutations of the mouse GNAQ gene, and the hyperpigmentation in these mutant mice is due to an increase of intradermal, but not epidermal melanocytes. It is important to note here, however, that these Dsk mutations are different from the oncogenic human $G N A Q$ mutation at codon position 209 [33]. Other studies in mice have shown that activating mutations in GNAQ or Galpha11, another gene encoding G-protein subunits, result in an aberrant accumulation of melanin-producing melanocytes in the dermal layer of the skin [15].

The finding that $G N A Q$-mutated melanocytic lesions (uveal melanoma, blue nevi [10, 26, 34] and our series of melanocytic lesions of the CNS) only infrequently carry $B R A F$, and NRAS mutations might be helpful for differential diagnostic purposes. For instance, in our series, one melanoma contained a GNAQ mutation, which, in the differential diagnosis with a metastasis of a primary cutaneous melanoma-often harboring BRAF or NRAS mutations - might favor a primary location in the CNS. So, the presence of $G N A Q$ mutations and lack of $B R A F$ or NRAS mutations in melanocytic neoplasms of the CNS seems to strongly indicate a primary CNS tumor, a diagnosis that has obvious prognostic implications. Vice versa, as $B R A F$ point mutations are a frequent event in cutaneous melanomas [30], the one melanoma in our series with a $B R A F$ point mutation (case 15; c.1799 $\mathrm{T}>\mathrm{A}$, p.V600E) might be a metastasis rather than a primary tumor. The fact that in this patient the tumor was located in the frontal lobe (rather than in the posterior fossa or around the spinal cord) might support this notion. However, according to the available data, a melanocytic tumor outside the CNS was absent in this patient. In our study, GNAQ mutations were preferentially present in the melanocytomas, while the intermediate melanocytomas and melanomas were only infrequently mutated. This might suggest that the presence of a $G N A Q$ mutation favors a benign or low-grade course. On the other hand, activating GNAQ mutations are also reported in uveal melanomas, and, in addition, are shown to have no effect on disease-free survival in these neoplasms [3]. In conclusion, mutations in the $G N A Q$ gene are a frequent event in primary melanocytic neoplasms of the CNS. This finding provides an important new insight in the pathogenesis of melanocytic CNS lesions, and suggests that $G N A Q$-dependent mitogen-activated kinase signaling is a promising therapeutic target in these tumors.

Acknowledgments We thank the PALGA foundation, the national histopathology and cytopathology databank in The Netherlands, for providing us with anonymized patient information.

Conflict of interest statement The authors declare that they have no conflict of interest. 
Open Access This article is distributed under the terms of the Creative Commons Attribution Noncommercial License which permits any noncommercial use, distribution, and reproduction in any medium, provided the original author(s) and source are credited.

\section{References}

1. Balmaceda CM, Fetell MR, O'Brien JL, Housepian EH (1993) Nevus of Ota and leptomeningeal melanocytic lesions. Neurology 43:381-386

2. Barbacid M (1987) ras genes. Annu Rev Biochem 56:779-827

3. Bauer J, Kilic E, Vaarwater J, Bastian BC, Garbe C, de KA (2009) Oncogenic GNAQ mutations are not correlated with disease-free survival in uveal melanoma. Br J Cancer 101:813-815

4. Bisceglia M, Carosi I, Fania M, Di CA, Lomuto M (1997) Nevus of Ota. Presentation of a case associated with a cellular blue nevus with suspected malignant degeneration and review of the literature. Pathologica 89:168-174

5. Brat DJ, Perry A (2007) Melanocytic lesions. In: Louis DN, Ohgaki H, Wiestler OD, Cavenee WK (eds) WHO classification of tumours of the central nervous system, 4th edn. IARC, Lyon, pp 181-183

6. Brat DJ, Giannini C, Scheithauer BW, Burger PC (1999) Primary melanocytic neoplasms of the central nervous systems. Am J Surg Pathol 23:745-754

7. Bullard DE, Cox EB, Seigler HF (1981) Central nervous system metastases in malignant melanoma. Neurosurgery 8:26-30

8. Burger PC, Scheithauer BW, Vogel FS (2009) Surgical pathology of the nervous system and its coverings. Churchill Livingstone, New York

9. Casparie M, Tiebosch AT, Burger G et al (2007) Pathology databanking and biobanking in The Netherlands, a central role for PALGA, the nationwide histopathology and cytopathology data network and archive. Cell Oncol 29:19-24

10. Cruz F III, Rubin BP, Wilson D et al (2003) Absence of BRAF and NRAS mutations in uveal melanoma. Cancer Res 63:5761-5766

11. Fecher LA, Amaravadi RK, Flaherty KT (2008) The MAPK pathway in melanoma. Curr Opin Oncol 20:183-189

12. Goldgeier MH, Klein LE, Klein-Angerer S, Moellmann G, Nordlund JJ (1984) The distribution of melanocytes in the leptomeninges of the human brain. J Invest Dermatol 82:235-238

13. Hocker T, Tsao H (2007) Ultraviolet radiation and melanoma: a systematic review and analysis of reported sequence variants. Hum Mutat 28:578-588

14. Horn EM, Nakaji P, Coons SW, Dickman CA (2008) Surgical treatment for intramedullary spinal cord melanocytomas. J Neurosurg Spine 9:48-54

15. Jackson IJ (2004) The G-netics of dark skin. Nat Genet 36:935936

16. Kadonaga JN, Frieden IJ (1991) Neurocutaneous melanosis: definition and review of the literature. J Am Acad Dermatol 24:747-755
17. Lamba S, Felicioni L, Buttitta F et al (2009) Mutational profile of GNAQQ209 in human tumors. PLoS One 4:e6833

18. Livingstone E, Claviez A, Spengler D et al (2009) Neurocutaneous melanosis: a fatal disease in early childhood. J Clin Oncol 27:2290-2291

19. Markby DW, Onrust R, Bourne HR (1993) Separate GTP binding and GTPase activating domains of a $\mathrm{G}$ alpha subunit. Science 262:1895-1901

20. Omholt K, Karsberg S, Platz A, Kanter L, Ringborg U, Hansson J (2002) Screening of N-ras codon 61 mutations in paired primary and metastatic cutaneous melanomas: mutations occur early and persist throughout tumor progression. Clin Cancer Res 8:34683474

21. Onken MD, Worley LA, Long MD et al (2008) Oncogenic mutations in GNAQ occur early in uveal melanoma. Invest Ophthalmol Vis Sci 49:5230-5234

22. Poynter JN, Elder JT, Fullen DR et al (2006) BRAF and NRAS mutations in melanoma and melanocytic nevi. Melanoma Res $16: 267-273$

23. Retsas S, Gershuny AR (1988) Central nervous system involvement in malignant melanoma. Cancer 61:1926-1934

24. Ross EM, Wilkie TM (2000) GTPase-activating proteins for heterotrimeric $G$ proteins: regulators of $G$ protein signaling (RGS) and RGS-like proteins. Annu Rev Biochem 69:795-827

25. Rutten I, Bolle S, Kaschten B, Stevenaert A, Deneufbourg JM, Deprez M (2005) Recurrent intracranial melanocytoma associated with a nevus of Ota. Acta Neurochir 147:313-315

26. Saldanha G, Purnell D, Fletcher A, Potter L, Gillies A, Pringle JH (2004) High BRAF mutation frequency does not characterize all melanocytic tumor types. Int J Cancer 111:705-710

27. Savitz MH (1987) Primary melanomas of the central nervous system. J Neurosurg 66:948

28. Shin MK, Levorse JM, Ingram RS, Tilghman SM (1999) The temporal requirement for endothelin receptor-B signalling during neural crest development. Nature 402:496-501

29. Skarli SO, Wolf AL, Kristt DA, Numaguchi Y (1994) Melanoma arising in a cervical spinal nerve root: report of a case with a benign course and malignant features. Neurosurgery 34:533-537

30. Thomas NE (2006) BRAF somatic mutations in malignant melanoma and melanocytic naevi. Melanoma Res 16:97-103

31. van Dongen JJ, Langerak AW, Bruggemann M et al (2003) Design and standardization of PCR primers and protocols for detection of clonal immunoglobulin and $\mathrm{T}$-cell receptor gene recombinations in suspect lymphoproliferations: report of the BIOMED-2 Concerted Action BMH4-CT98-3936. Leukemia 17:2257-2317

32. Van Raamsdonk CD, Bezrookove V, Green G et al (2009) Frequent somatic mutations of GNAQ in uveal melanoma and blue naevi. Nature 457:599-602

33. Van Raamsdonk CD, Fitch KR, Fuchs H, de Angelis MH, Barsh GS (2004) Effects of G-protein mutations on skin color. Nat Genet 36:961-968

34. Yazdi AS, Palmedo G, Flaig MJ et al (2003) Mutations of the BRAF gene in benign and malignant melanocytic lesions. J Invest Dermatol 121:1160-1162 